\title{
EXCURSUS - POSTALES DE LA ENFERMEDAD COVID-19
}

\section{EXCURSUS - POSTCARDS OF COVID-19}

\section{Armando S. Andruet (h) ${ }^{1}$}

DOI: https://doi.org/10.37767/2591-3476(2020)14

Propongo en esta contribución, realizar un breve repaso de algunas impresiones que el acontecimiento pandémico nos ha suscitado y que consideramos, que pueden ser de interés compartirlas para desarrollar futuros abordajes y perspectivas de la actualidad de la evolución que el mismo proceso de la enfermedad de COVID-19 nos ha propuesto a todos nosotros.

Todas estas impresiones son al fin, resultado de una gran perplejidad -no seguramente como la que habrá tenido Averrroes- que la enfermedad pandémica ha causado en el hombre del siglo XXI y por ello, no tan insignificantes las mismas como para despreciarlas. Su resultado es parcialmente el que ahora compartimos y del cual, también debemos advertir que no busque el lector en ellos un aporte de un trabajo erudito, júzguese el mismo, como un tránsito en las intersecciones que encuentra raíces en lo espiritual, moral y cultural.

\section{Acerca de la interpelación ética que la pandemia produce}

Sin duda alguna que doscientos veinte días atrás, concomitante con los festejos por el nuevo año 2020 que se inauguraba en nuestro calendario, pocos podíamos imaginar que el mundo cambiaría en una forma tan drástica y veloz.

Hace solo siete meses -como corrientemente se puede admitir-, China detectaba los primeros casos de un tipo de influenza que tenía una sintomatología diferente a las anteriores, y que tampoco reaccionaba dicha enfermedad como era esperado con las medicaciones estándares. Hoy sabemos de qué se trata, cómo nos enfermamos, cómo nos cuidamos y todavía ignoramos terapéuticamente cómo la podemos enfrentar, más allá que todo parece indicar, que en los próximos meses la vacuna sanadora habrá llegado como opción salvífica.

El mundo ha retrocedido a un modelo medieval del cuidado físico de la salud, que parece ser, lo que nos demuestra inequívocamente que la biología y la enfermedad humana, en tiempos donde hemos descubierto como construir una molécula de vida sintética, no tiene sin embargo una respuesta válida y eficaz desde lo tecnológico y con ello, dando la espalda los juicios generosos y encendidos de médicos de la estatura de Henry Sigerist o de Sir MacFarlane Burnet, este último Premio Nobel en Fisiología, quienes coincidían en pensar que las enfermedades infecciosas en términos generales habían sido vencidas (Sigerist, 1946; Burnet, 2007). 
La biología supera cualquier parámetro de desarrollo tecnológico. Quizás sea ello un buen llamado de atención a que los sueños fáusticos de los científicos, nunca serán mayores a los que la naturaleza siempre puede hacer con ellos (Harari, 2014).

Doscientos veinte días atrás, cuando creíamos que las cosas seguirían avanzando tal como la lógica de las rutinas de las cuestiones normales se presentaban, hemos sufrido un giro de campana tan severo, que autoriza pensar, que somos privilegiados -y también responsables- por ser los actores de un cambio de época en la civilización de la humanidad. La pregunta ínsita a ello es, cuáles deberían ser los elementos que esa nueva época, pos-pandémica, debería privilegiar o proyectar con mayor énfasis para el nuevo período histórico (Andruet, 2020).

Es entonces una buena oportunidad, el saber aprovechar el acontecimiento de la pandemia como hecho central de los sucesos en los cuales estamos incursos, para hacer entonces de la 'crisis' la fortaleza y el motor de la transformación de las cosas para que ellas sean diferentes y mejores a lo que son hoy.

Ese sin duda es el esfuerzo que está detrás del malestar. Quizás como ninguna otra lengua, el vocablo 'crisis' en chino -atento el grado cero de la pandemia y tópico del cambio de época- se compone de dos caracteres: wei y ji, esto es 'peligro' y ‘oportunidad'.

De la misma forma nuestra palabra latina 'crisis' tiene su antecedente en otra griega krisis que se referencia inmediatamente con 'decisión'. Con ello, la 'crisis' que habitualmente vinculamos como un 'momento decisivo en un asunto de importancia'; es el tiempo en donde hay decisiones que se deben tomar para desbaratar el peligro que se muestra en el presente y tener la decisión de hacer de ello, una oportunidad para un triunfo ulterior. Por los días que corren, temporalmente pocos desde que se inició el proceso y a la vez, de tanta densidad por lo que ellos han significado; ciertamente todavía estamos en tiempos de peligro. Ni siquiera sabemos cuántas otras personas habrán de enfermar y de ellas morir; pero dicha circunstancia no nos debe privar de reflexionar sobre las oportunidades en el futuro.

Quizás sea nuestro tiempo propicio para actualizar el 'principio de precaución' de Hans Jonas (1995), sobre la base de que las generaciones futuras de un mundo más humano -en sentido auténtico- no es proyectable a mediano plazo, tal como hasta hoy lo venimos haciendo, sino que debería colocarse como meta a muy corto plazo. Esto es: antes que la memoria generacional haya sido oscurecida por nuevos acontecimientos, que si bien quizás no serán semejantes a éste, podrán ser igualmente importantes.

Quizás el desafío de hombres y mujeres a la altura de los tiempos que corren, sea el de superar el 'peligro' y proyectarse en las 'oportunidades'.

Oportunidades de un mundo mejor en donde las utopías de A. Huxley queden atrás, y sean estas otras que el peligro ha puesto de manifiesto que pueden ser cumplidas; pero conquistarlas como un logro de la razón común de la humanidad y no como el resultado colectivo del temor al enemigo colectivo como es el COVID-19.

Si naturalmente el conjunto humano no es capaz de pensar y orientar la acción en dichos términos, sin duda alguna que la 'catástrofe' biológica en la que nos encontramos y que 
se ha multiplicado después, en una infinita cantidad de reverberancias catastróficas: en lo social, individual, económico, laboral, industrial y una extensa lista de etc.; pues que habremos hecho de la 'catástrofe' algo todavía peor, esto es, para decirlo en palabras de Ernesto Garzón Valdés (2004) una auténtica 'calamidad'.

Las catástrofes son desastres naturales, cuestiones no intencionales del hombre; las calamidades tienen una causalidad humana; y cuando el hombre no quiere hacer nada para modificar las condiciones para un mundo mejor, realiza una acción calamitosa, conjuga calamidades y se convierten dichos intercambios en los modos propios de una sociedad de canallas.

Doscientos veinte días atrás, no dudábamos por un instante que los países con mayor desarrollo en la industria tecnológica seguirían avanzando en la lucha acerca de cuál de ellos, gobernaría el prometeico desarrollo de la inteligencia artificial y con ello, hacerlo también sobre las economías completas de los mercados; no desconocíamos que las guerras entre diversas etnias en el mundo por controles de territorios o la imposición ideológica iban a continuar; sabíamos que las bolsas cambiarias del mundo asfixian a empresas y países en pocas horas hasta humillarlos en el valor de sus acciones; suponíamos que se iban a profundizar las sustituciones de la vida biográfica de las personas por las vidas virtuales; descontábamos que los migrantes serían cada vez más numerosos como así también, del crecimiento geométrico de franjas con mayor pobreza y profundas desigualdades sociales, todo ello lo sabíamos. Nos dolíamos de tales sucesos verdaderamente despiadados, pero era sencillamente lo tristemente previsible.

Es decir que los acontecimientos que vislumbramos como posibles a finales del año 2019 -doscientos veinte días atrás-, no podían ser sino, los que naturalmente se podían producir y/o agravar, en la economía, tecnología, guerras, mercados, pobreza y desigualdad. Nuestro abecedario universal de pocas letras seguía antes de la pandemia y continúa incluso cuando ella está siendo cursada, sin contabilizar en general, los comportamientos éticos de las instituciones, de las empresas o de las personas (García Marza, 2011).

Ello sin duda que responde al modelo de hombre que el siglo XXI ha logrado consolidar como estereotipo, en donde existe una licuación de una idea de un mundo mejor en clave de un mundo más ético y responsable para decirlo en palabras de Zigmunt Bauman (2010) y donde la idea clásica del humanismo aun siga teniendo entidad (Fernández de Arroyabe, 2003). La sociedad contemporánea en buena medida, ha cambiado un modo ético de vida por una cosmética ética en la cual, el conformismo con las cosas como están, es la hipótesis a lograr, y para ello, ha inoculado en muchos ámbitos, que la sola dimensión de la 'solidaridad' es el componente ético por antonomasia en las sociedades modernas y ello es por si solo suficiente. Lo cual sin duda que no es verdadero. La solidaridad no alcanza pero sin ella es imposible cualquier logro en dicho capítulo (Lipovetsky, 1994).

Nada tenemos en contra de la solidaridad y en general en tiempos de catástrofe ella se manifiesta muy activa en nuestros países de tradición latina y es muy importante y valioso que ello así se manifieste. Pero de nuevo, lo importante es poder mirar las cosas no en tiempos de catástrofe sino de quietud y normalidad.

Es muy probable que la solidaridad en tiempos de dicho desorden, y allí la centralidad de nuestra tesis, esté movida por intereses atravesados por el propio egoísmo individual, 
en cuanto las personas vean reflejadas en los otros, lo que también les puede ocurrir a ellas. Esto es, ver el dolor del otro como propio no en cuanto situación empática sino meramente disparadora de nuestro propio futuro y por ello, el ser solidario con ellos, es con mezquindad futura por el propio trato que se quiere tener para consigo. Sin duda que pensar la solidaridad de ese modo es de canallas, es cierto, pero no se puede negar que hay muchas personas que así la han pensado por estos tiempos de enfermedad global.

Por ello para intentar evitar la calamidad de mañana, se pueden cumplir pequeños comportamientos morales de cada uno, para que difuminen ellos en el espacio que a cada quien le toca ocupar; una praxis que demuestre que no le ha sido indiferente la catástrofe. Seguramente la suma de las voluntades individuales no hace al comportamiento del todo, pero al menos puede poner en mayor relevancia la desidia ética de quien tiene más responsabilidad en dicho todo.

Las personas que tienen espacios institucionales de mucha o poca responsabilidad en la toma de decisiones, es mucho lo que pueden hacer, cuando lo que hacen, lo cumplen con la convicción ética de hacerlo con integridad, honestidad, prudencia y eficacia. Así las cosas pueden ser mejores, cuando uno mismo intenta ser íntegro desde el lugar en que se encuentra. Ello es tan sencillo como hacer bien lo que se debe hacer (Cortina, 2010). Llegará un momento donde se nos interpelará a todos nosotros respecto a cuanto hemos hecho con nuestras acciones sociales para evitar la calamidad. A ello responderemos positivamente mostrando la responsabilidad ética que hemos puesto en cada una de las cosas que de nosotros dependen.

Y cuando ello no sea posible, que cada quien sepa, que lleva colgada de sus ropas -como los leprosos siete siglos atrás- una campanilla que avisaba a los demás que era un enfermo (Gracia y Peset, 1978).

La enfermedad hoy que no es la biológica sino la ética, es la de no ser una persona íntegra y por ello, que se ha comprometido más que solidariamente con los demás. No hacerlo así, es colectivamente como sociedad algo más grave a lo que cualquier catástrofe nos puede traer, porque es una auténtica calamidad de la especie.

\section{Señales virtuales en un mundo de enfermedades reales - El peligro de la disolu- ción antropológica}

Queremos referirnos ahora, a algunas impresiones que registramos de un mundo enfermo, y que si bien en un primer momento para un lector desprevenido pueden parecer ellas un exceso, respondemos que cuando el telón se corra, veremos la verdadera estatura de los personajes. La escenografía de los tiempos que están corriendo, oculta en muchas ocasiones el juego de los personajes en la misma.

En realidad creemos, que la vida de todos nosotros ha quedado como quien diría, 'atravesada' y 'perforada' por el acontecimiento de la pandemia y su entrañable compañera de viaje con independencia que lo sea por largo o corto plazo, como es la cuarentena (Delumeau, 2019); y que hasta donde se ha podido conocer en algunos casos, ella ha impuesto de grandes esfuerzos físicos, morales y espirituales a las personas para sobrellevar el tiempo con alguna cuota de éxito al final del camino y en otros casos, resultaron los mismos insuficientes y todo el esfuerzo pareció despedazarse sin ninguna ganancia o provecho para los abnegados ciudadanos. 
Lo cierto es que ninguna de nuestras vidas por lo pronto, es igual a la que con anterioridad teníamos, empezando por el mismo hecho de estar privados de movernos a donde nos parezca que hay que hacerlo, porque muchos todavía mantienen la exigencia de guardar cuarentena con todas las implicancias que desde una teoría del control social se pueden configurar con ello (Mora, 2005). Cantidad de ciudadanos impedidos de poder trabajar y sabiendo que para muchos de esos afectados, dichas restricciones son iguales a no poder acceder a sus fuentes de trabajo y por ello, no poder satisfacer sus necesidades básicas. A ello no se puede dejar de agregar las carencias y limitaciones de poder establecer la sociabilidad que las personas requieren mínimamente, como complemento a su forma de vida, todo ello entre otra extensa lista de impedimentos.

Tampoco podemos negar que cuando esto concluya y cada uno vuelva a recuperar el oxígeno del mundo exterior, habremos de descubrir que las cosas no son iguales a las que dejamos. No sólo por lo que, para el tránsito diario de lo económico toda la pandemia habrá de significar en cada uno de nosotros, y que para unos será muy grave $y$, para otros algo menos; pero en ese aspecto el COVID-19 nos ha enfermado a todos, aunque biológicamente lo haya hecho solo con una parte importante del colectivo social (Andruet, 2020).

Fuera de lo económico, las reconstrucciones de los tejidos sociales será también una tarea que demandará buen tiempo y ojalá pueda ser cumplida dicha tarea de la mejor forma posible.

Algunas instituciones, empresas y personas, habrán descubierto que el 'mundo virtual' es muy importante y que ha resultado ser exitoso en la emergencia para sortear una infinita cantidad de problemas (Queau, 1995). De allí sin embargo, hay quienes obtienen conclusiones equivocadas o al menos precipitadas. Entre ellas, se ha pretendido convencer socialmente que los empleados del ámbito privado y público, pueden cumplir con eficacia y eficiencia el teletrabajo; que los alumnos de todos los niveles de los ciclos generales han seguido su secuencia del proceso enseñanza-aprendizaje sin mayores complicaciones y disfunciones; que los alumnos universitarios de la mayoría de las carreras, han continuado sus estudios sin grandes inconvenientes. Y tantas otras cosas más. Nada de ello es mentira, sin embargo todo es parcialmente verdadero.

La cuestión será indagar detenidamente si todo eso, con independencia de las cuestiones puramente operativas y no quisiéramos decir cuasi mecánicas -y que son del puro trámite que toda práctica social estandarizada lo posee- realmente han sido satisfactorias (Du Gay, 2012). Sumamos, de todas maneras que las cuestiones de rutina no por serlas de ese modo no son de importancia. Sin embargo el grueso de las cuestiones que hemos listado en el párrafo anterior, tienen aspectos que no son mecánicos ni de rutina y por lo tanto, esos segmentos han tenido que ser seccionados, ignorados o retirados de esa entrega virtual por el simple hecho, que no se pueden transferir.

Los más entusiastas del mundo virtual, habrán de decir que se cumple con ellas de otra manera a lo que corresponde decir, que si es de otra manera, se trata entonces de una cuestión diferente y no aquélla, que apreciábamos como sustantiva. Esa es la obviedad que a veces no se entiende en forma completa.

Por de pronto queremos señalar, que todas las prácticas sociales tienen necesariamente 
un contexto en el cual ellas se brindan y esa pragmática (Ducrot et. al, 1998), tiene naturales condiciones escénicas que le dan la entidad correspondiente al acto de que se trate. No es lo mismo 'estar' en una ceremonia religiosa en un templo, que 'seguirla' por cualquiera de las plataformas que inesperadamente hemos reconocido en los últimos meses. En un ámbito somos un 'activo' del marco escenográfico y en el otro, somos 'observadores' que cada tanto, pueden llegar a representarse también, como responsables del oficio religioso.

Podrá indicar la persona que ha participado de la ceremonia, ello es cierto, que lo ha hecho, pero muy difícilmente se ha sentido compelido al acto de constricción que supone dicho momento, cuando a su alrededor el escenario es el doméstico con las comodidades o no que pueda tener. No se trata de una cuestión de confort, es una definición espacio-espiritual en dicho caso, y que no es emulable, aunque a su espalda, se escuche la interpretación de la misa solemne de Beethoven.

Que los padres se hayan convertido de pronto en los instructores de docencia a sus hijos más pequeños; y que bien conocemos de ello, porque hemos estado a veces enfermos de niños y los días que no estábamos en clase eran suplidos con asistencias domésticas de nuestros padres y no implicaba disminución en nuestro aprendizaje, ello también es cierto. Pero de allí, creer que lo hecho hasta ahora con el mejor esfuerzo de los padres es lo mismo, próximo o parecido a lo que hace un maestro realiza en el espacio áulico, es simplemente engañarse.

No porque los padres no hayan puesto su voluntad y empeño, y las criaturas la parte que les corresponde; sino de nuevo, son los contextos escénicos de la institucionalidad escolar quien ha demarcado que en las escuelas, primariamente se aprende y ello no es trasladable al espacio doméstico, donde en el mejor de los casos, se habrá de reforzar aquello pero muy difícilmente generarlo.

Finalmente para esta mención, creemos que también habrá que estar muy precavido de las apreciaciones que los tecnócratas de la virtualidad habrán de indicar, y que no implica despreciar lo que se ha cumplido intermediado por la tecnología virtual; pues existen espacios que van desde los institucionales hasta los amicales, en donde la pantalla del artefacto que sea: PC, Tablet, Smartphone, nunca es igual al rostro del otro. El rostro siempre es el límite que el otro nos coloca, si lo reconocemos pues que respeto la persona, si lo sobrepasamos quizás la humillemos. El rostro de ese que está a nuestro frente, que nos interpela de tantas formas sin decir nada; y ello ninguna pantalla puede emular, puesto que una cosa es poder 'ver' incluso 'mirar' la imagen de un rostro, pero eso no es dejarme interpelar por el rostro del otro, tal como Emmanuel Levinas en su obra sugiere (Levinas, 2000).

Pensemos en temas institucionales judiciales. Por caso, es cierto que los Tribunales han cumplido audiencias mediante el modo virtual; ahora bien, que se puedan haber cumplido exitosamente dichas acciones, no significa que ese sea el óptimo al cual hay que tender. Es la emergencia la que impone una transformación de lo que se encuentra institucionalizado como 'estable', por una formulación 'precaria', lo cual no quiere decir que no se pueda naturalizar lo virtual para ciertas cuestiones y que incluso pueden ser cuantitativamente numerosas.

No es nuestro reparo por ninguna falta de legalidad que los actos puedan tener, ello es 
completamente salvable, sino en todos los casos, por la desmaterialización de la dimensión antropológica que se produce en las cuestiones que son innatamente humanas. Ponemos en duda, si dimensiones que se relacionan de tal modo con la experiencia límite que tienen las personas, son posibles de ser instrumentalizadas en modo general por el mundo virtual, pues por caso: Juzgar, Educar, Curar. Con mucha más razón, toda la pléyade de vínculos no institucionales que establecemos y que requieren de esa relación que nos roza en lo íntimo, así las afectivas y las amicales.

Pues comenzamos diciendo que nada será igual para nadie cuando todo esto concluya, aunque en realidad también debemos decir, que las consecuencias serán más severas que el hecho mismo de la enfermedad. Y ello en realidad es lo que siempre ha sucedido en la historia de los pueblos que han sufrido este tipo de acontecimientos biológicos a escala digamos hoy, global. Las pandemias o pestes como eran nombradas en la antigüedad, han modificado el curso de la historias de los pueblos y de las personas (Snowden, 2020).

Han caído imperios centenarios, se han fortalecido religiones, han producido aportes sustantivos para la medicina, ha promovido fuertes perversidades en la naturaleza humana y también gestos de fraternidad impensados.

Deberemos ser cautos en el nuevo territorio pospandémico para no ser colonizados, por un mundo virtual y digital que se presente como generoso en eficacia, con bajo costo operativo y elevada eficacia técnica (Van Dick, 2016). Todos nosotros seguiremos necesitando durante un tiempo todavía extenso, concluida la enfermedad, de la apoyatura tecnológica y no debemos negarla, pero debemos pensar que ella no solo que sigue siendo provisoria, sino que conspira con lo único que no puede ser reemplazado en el mundo virtual y que es lo humano.

\section{Tristes rostros de la estupidez humana en tiempos pandémicos}

En el momento de conocer la información periodística de la que daremos cuenta, no parecía razonable para nada. Sin embargo las fuentes eran confiables y no era penosamente una más, de las tantas viralizaciones que las redes promueven; la habían reproducido diarios de prestigio ${ }^{2}$. La sorpresa concluyó, cuando nuestras lecturas terminaron por hacer realidad el primer disparo intelectual que tuvimos cuando de ella conocimos por sus titulares. Concluimos sin más, que la estupidez de las personas (Mascaro y Porcar, $1986)^{3}$, en alguna de ellas no es limitada sino que es insondable y las muestras quedan expuestas a la vista de todos, todos los días.

Ya lo había señalado en un libro que fue muy conocido algunas décadas atrás y quizás ayudó a que muchas de las personas que lo leímos -recuerdo haberlo hecho sobre mediados de los ochenta-, nos ayudó -solo parcialmente- a ser algo menos estúpidos. Me refiero a la obra del Prof. húngaro y nacionalizado británico Paul Tabori, que en 1964 escribiera 'Historia de la estupidez humana', y que se editó en nuestro país por editorial Siglo Veinte en 1966 y que tenía una breve introducción de Richard Armour que comienza así: "Algunos nacen estúpidos, otros alcanzan el estado de estupidez, y hay individuos a quienes la estupidez se les adhiere. Pero la mayoría son estúpidos no por influencia de sus antepasados o de sus contemporáneos. Es el resultado de un duro esfuerzo personal".

\footnotetext{
2 Vide entre otros medios, El Mundo de España, Clarín de Argentina (https://www.clarin.com/internacional/estados-unidos/coronavirus-unidosorganizan-fiestas-premiar-primero-contagia-covid-19_0_zsd8xjgB1.html), New York Times de EE.UU.

3 No nos estamos refiriendo en esta ocasión a la 'estupidez', tal como es reconocida en el ámbito médico como "incapacidad profunda de las facultades intelectuales, generalmente congénita” (Mascaró y Porcar, 1986, pág. 191).
} 
En 'tiempos pandémicos' como son los actuales, hemos encontrado ejemplos especiales de la mayor síntesis de la estupidez; mediante la cohabitación deliberada entre el hombre (estúpido) y la enfermedad del COVID-19.

Como sabemos, en el mundo desde hace algunos meses a esta parte, se ha desatado una auténtica carrera de la industria farmacéutica vinculada a los grandes centros de investigación a los fines de desarrollar exitosamente la tan ansiada vacuna que ponga límites al COVID-19, cuestión ésta, que si bien podrá tener diversos intereses por detrás, desde económicos a altruistas; mas lo cierto es que con ella se habrán de establecer los resguardos suficientes para los sistemas inmunitarios de las personas y dar con tal desarrollo, por iniciado el trayecto de la convencionalización de la enfermedad en términos generales.

Hasta que ello ocurra, los Estados y las personas, nos deberemos mover con la máxima responsabilidad, entendiendo que podemos ofrecer poca resistencia a la enfermedad y que la transitoriedad del estado de gravedad sanitaria, nos impone y autoriza a tener que tomar con cierta adaptabilidad de situación normal, aquello que definitivamente no lo es, y por ello, como aportaremos en la postal siguiente. Negamos nombrar la singularidad de nuestro vivir contemporáneo bajo el concepto de 'nueva normalidad'; siendo este acontecer de nuestra realidad, la anormalidad en la transitoriedad de una enfermedad pandémica.

Mas lo leído en los diarios antes citados, sobrepasa todo criterio de anormalidad por la enfermedad, es una extraña confusión de estupidez y relajamiento moral.

Pues las informaciones en cuestión indican, que el Estado de Texas acorde los últimos datos, es el cuarto más numeroso en contagios en los EE.UU. con 596.000 infectados, y las muertes superan las 11.000 personas. Sin embargo, todavía hay personas -bastante estúpidas- que consideran que el COVID-19 es un invento de los Estados, de los gobernantes o de los medios de comunicación entre otros efectores mendaces, y por ello, deciden poner a prueba su misma inmunidad al virus en una fiesta, para la cual, todos colocan dinero a modo de entrada, y en la cual, como en un buen proyecto experimental, hay también invitados que son positivos de la enfermedad y que muy pocos conocen quienes son -y seguramente no participarán de la reunión- con ello por delante, los desafiantes del reto; se divierten toda la noche y quizás enfermen o no enfermen.

Diríamos que es una metodología contrapuesta a todo método ciego, pues los enfermos saben que todos los demás son sanos y por ello, su función indigna es exponer y propagar la enfermedad. Pues si algunos son estúpidos, está claro que otros son perversos.

El premio -que paradojalmente ha incentivado la presencia el macabro evento-, es para quien sea el primero en reportar estar contagiado de coronavirus, y será quien se lleva lo recaudado con la venta de las entradas y eventualmente también, por el mismo costo, se puede adjudicar el podio principal que la enfermedad de SARS-CoV-2 puede ofertar, como lo fuera para un joven de 30 años de edad, quien luego de estar hospitalizado en el Hospital Metodista de San Antonio falleció y que hizo el relato de lo sucedido a la doctora Jane Appleby, directora médica del nosocomio.

Otra de las fuentes señalan, que "al menos una persona en Kentucky se contagió de covid-19 después de participar en una 'fiesta de coronavirus' con un grupo de adultos jóvenes, dijo el gobernador Andy Beshear". De las informaciones todo parece orientar a un grupo de jó- 
venes universitarios de la ciudad de Tuscaloosa del Estado de Alabama, quienes habrían sido los promotores de las diabólicas como estúpidas reuniones.

Mientras escribimos esta postal, pensamos en la racionalidad y responsabilidad que todos nosotros colocamos a diario en evitar aglomeraciones, en privarnos de reuniones y tantas otras cosas; porque tenemos la certeza no solo que la enfermedad existe sino que también, bajo determinadas condiciones de las personas, es muy probable que también cause la muerte.

Sin embargo también he reparado, y haciendo abstracción de las metodologías que puedan estar en curso ahora y que seguramente no existían en siglos anteriores; que los tiempos de las pestes en muchas personas -antes que hoy-, promocionan sensaciones de vacío existencial y de muerte cuasi segura y quizás por ello, a muchas de ellas, no les quedaba otra cosa que entregarse al máximo disfrute del placer orgiástico, porque la muerte era un dato de la realidad inmediata.

Así lo relata el propio Tucídides cuando en el Libro Il de la 'Historia del Peloponeso' recordando la epidemia de Atenas del 430 a.c., indica que el relajamiento moral era notable y que "Ia peste introdujo en Atenas otro tipo de inmoralidades aún más graves; las personas se entregaban al placer con un descaro nunca visto" (Tucídides, 1976).

De alguna manera ello es también reflejado por el mismo Giovanni Boccaccio en la introducción al El Decamerón, en donde dicho autor, como espectador en primera persona de la 'Peste Negra' (1348-1352) que asoló especialmente a Florencia, relata los diez días con los cien cuentos, que los diez jóvenes -7 mujeres y 3 hombres- se contaría cada día, para con ello, refrescar su dolor por la epidemia y dibujando detrás de muchos de los cuentos, diversas fantasías eróticas.

En los dos casos está la pandemia, en ambos el núcleo central es la huida que el hombre realiza de la enfermedad, ya sea por el desenfreno de la lujuria o por la sublimación de la belleza poética; pero en realidad lo que ahora conocemos por los periódicos, no es la fuga de la enfermedad sino lo contrario, esto es, ir a su encuentro; como si ella fuera inexorable o inexistente, lo cual resulta inexplicable en cualquiera de los extremos dichos.

En realidad tal cuadro biográfico ante la enfermedad del COVID-19 en estas personas que salen a su encuentro, desafiando con su juventud el ejército del virus que está presto para apoderarse de los cuerpos; parecen encarnar una especie invertida del 'ars moriendi' (arte de morir) del bajo medioevo y que era la forma posible, en que el propio hombre, a veces en su lecho de enfermo, podía subvertir su historia negativa del pasado, encontrando la redención necesaria y con ello, reinventar su misma historia individual de pecador (Sanmartin Bastida, 2006).

Los jóvenes de las 'fiestas del coronavirus', inauguran un estúpido modo de ars vivendi (arte de vivir) que intenta desafiar lo que no siempre está permitido, como son las reglas del sentido común (Garrigou-Lagrange, 2006). Las estadísticas epidemiológicas que indican que los jóvenes no son quienes más mueren por COVID-19 son reales, pero ello no implica que algunos puedan morir.

Nadie puede sentirse completamente inmune ante la pandemia, creerlo así, tal como 
advertimos a nuestro alrededor; permite darle crédito a las últimas palabras del párrafo final de Tabori: "Fin... pero la estupidez humana no tiene fin".

\section{Tiempos pandémicos y la 'nueva normalidad'}

Es relativamente conocido para todos nosotros, que los momentos socio-culturales en los cuales nos viene a corresponder vivir, habrán de estar signadas por lo que se conoce como los 'signos de los tiempos'. Tal apreciación se refiere a cuestiones profundas, que naturalmente calan en las dimensiones antropológicas, filosóficas y trascendentes en la cual dicho hombre se encuentra inmerso.

Así tales signos, pueden estar materializados en una cultura de la maximización del consumo y del hedonismo, puede por el contrario estar matrizados bajo una idea de la contemplación o por el espíritu del capitalismo o en su defecto, un ideal de beneficencia. Acaso por una cultura que exacerbe los derechos individuales o por el contrario, una apertura a la dimensión social del hombre.

Más de ello no queremos ocuparnos ahora. No buscamos describir signos de los tiempos; en realidad aspiramos presentar algo que está en una escala menor y que nombramos como las 'pequeñas culturas' que una determinada presencia epocal construye, y la sociedad asimila; hasta que finalmente puede que quede internalizada en las prácticas y los usos corrientes de ese colectivo social.

En alguna medida, los aspectos a los cuales nos estamos refiriendo, se vinculan con lo que algunos autores han considerado bajo el concepto lato sensu de la 'sociología de la moda' (Konig, 1968) y un proceso más o menos corriente de 'aculturación' (Gallino, 2005). Esto es, no viendo allí meramente una cuestión de vestimentas y presencias de la persona en la sociedad, sino las diversas maneras en que un determinado fenómeno epocal ha logrado colonizar las personas en modo evidente y en la mayoría de los supuestos puede que no exista siquiera disfrute por ello, sino simplemente una circunstancia de inercia que en la medida que ella más se consolida, deviene más complejo, discutir su asiento socio-cultural ${ }^{4}$.

Que no cabe duda alguna desde nuestra mirada, que el suceso sanitario del COVID-19 que asola desde finales del año anterior al planeta y que ha enfermado a 23.400 .000 personas y matado a otras 809.000; como que también, ha destruido económicamente hablando personas, empresas y fábricas. Y en algunos casos ha sido tan severa su fuerza dañina, que financieramente ha arrasado con países completos.

Semejante fenómeno sanitario, bien permite hablar de que el tiempo por el cual atravesamos y seguramente en el cual habremos de estar por varios años, no puede ser nombrado más apropiadamente como de un 'tiempo pandémico'. Y como tiempo pandémico que es, ha prodigado un conjunto de comportamientos, prácticas, realizaciones, maneras de pensar, relacionarse, estudiar, trabajar, disfrutar del ocio, conjugar lo familiar con lo social, etc., que ha resultado completamente innovador.

No queremos describir por innecesario, la extensa lista de cuestiones que ninguno de nosotros jamás pensamos vivir. Sin embargo han sido vividas y posiblemente todavía nos falten de conocer algunas otras, aún más graves.

4 Buenas referencias de ello nos brinda la obra de Elias, Norbert. El proceso de la civilización - Investigaciones sociogenéicas y psicogenéticas. Buenos Aires: F.C.E., 1993. 
Lo cierto es que el 'tiempo pandémico' nos ha colonizado en muchas cuestiones, a veces por imperio de las normas que han resultado apropiadas para conducir sanitariamente la emergencia y en otros supuestos, porque no habiendo imposición de ello, las mismas circunstancias de la realidad nos hacen creer que es lo más conveniente que sean de una manera novedosa.

Advertimos entonces, que se encuentra absolutamente consolidado dentro del discurso no solo institucional sino también del habitual y societario en general; que hay en ellos una referencia a que cuando, se empiecen a dejar atrás, los efectos más graves y elocuentes de la pandemia, y entonces la baja de la marea descubra de nuevo la arena existente -o lo que quede de ella- en dicha playa, es cuando podremos reconocer la vastedad de la gravedad, la envergadura del daño y entonces, habrá que saber encontrar la manera y los instrumentos junto con los recursos económicos para enfrentar lo que por doquier se nombra como la 'nueva normalidad'.

Sintagma éste, al que en verdad no prestamos completa atención hasta no hace mucho tiempo, puesto que nos parecía como de ocasión su evocación. Estaba en nuestro parecer, muy lejos de ser dicho nombre el que conceptualmente registraría lo que habremos de experimentar en el terreno de la realización social cuando la pandemia se retire.

Destaco entonces, que detrás de la 'nueva normalidad', se encierra un conjunto bastante heterogéneo de cuestiones, que mezclan los hábitos no solo higiénicos y preventivos de las personas, sino la forma de brindarnos los tratos sociales y afectivos y que se proyectan también en realizaciones de mayor vigilancia y control ciudadano.

Las diversas y extravagantes maneras que parece, que serán sugeridas para cumplir con las funciones laborales en el ámbito público y privado, como también las peligrosas intromisiones que en la libertad ambulatoria y la intimidad de las personas se habrán de producir, todo siempre en defensa de la lucha por la pandemia que aunque ella haya quedado atrás, siempre habrá interesados en que no se olvide el peligro latente de su rebrote. Y con ello por delante, al amparo del sanitarismo político, estará la ocasión para continuar haciendo lo que muchos Estados han encontrado con deleite biopolítico poder hacer: controlar (Foucault, 1989).

Pero tampoco es ese ahora el problema sobre el cual queremos apuntar unas líneas. Volvemos a señalar que se trata de una cuestión más simple como tópico, aunque con un efecto de gravedad notable. Pues solo para tomar un ejemplo del fatigoso número que de ellos existe, días atrás un periódico nos traslada la información acerca de "¿Qué hacer con el cubrebocas cuando salimos a comer en la nueva normalidad? - Su uso, pretende impedir la diseminación de microrganismos que se alojan en boca, nariz y garganta"s.

La pregunta que nos suscita ello, es si resulta correcto hablar de una 'nueva normalidad'. En realidad creemos que bajo aspecto alguno es lo adecuado, por lo pronto, la normalidad de las cosas, y las prácticas de las personas; está siempre en el marco de lo que ha ganado una cierta habitualidad para un conjunto, en principio, importante de individuos. Es parte de la normalidad que se cumplan con ciertos hábitos, por ejemplo respecto al trato social en general y que ello no implica que sean todos ellos igualmente uniformes,

5 Disponible en: https://www.infobae.com/america/mexico/2020/07/05/que-hacer-con-el-cubrebocas-cuando-salimos-a-comer-en-la-nueva-normalidad/. Última consulta 8.VII.20. 
sino que es cierto también, que cada estrato social de hecho, tiene normalidades que son comprensibles y aceptables en ese círculo, pero serian juzgadas como anormales en otro.

Muchos de nosotros cuando saludamos a una persona que nos acaban de presentar, lo 'normal' es extender la mano, mientras que si a ella la conocemos y guardamos afecto, posiblemente le brindemos un abrazo; en otros ámbitos, esa misma práctica es vista negativamente. Al menos así lo era, muchos años atrás cuando visitamos Japón, que no era para nada bien visto, pretender estrechar la mano del interlocutor.

Entonces por de pronto deberíamos repensar, si lo que nombramos como 'normalidad' es simplemente la habitualidad con la cual cumplimos determinadas prácticas. Y si es cierta, la noticia que hemos copiado más arriba: 'comer públicamente con cubreboca'; será una prueba de destreza interesante de sortear. Ahora, es ello la ¿nueva normalidad?.

Por de pronto más parece ser la idolatría a la anormalidad impuesta por la necesidad, pero creer que algo tan contranatural puede llegar a ser concedido como una 'nueva normalidad', nos parece que es tomar con poca seriedad las circunstancias emergenciales que como tal, imponen algunas transformaciones graves y extrañas, pero que siempre son precarias.

Todos nosotros hemos tenido situaciones excepcionalmente graves en algún momento de nuestras vidas, y ellas nos han llevado a realizar acciones también extraordinarias, extrañas y confusas; pero cuando lo excepcional desapareció, las hemos visto solo como anormales y no se nos ha ocurrido pensar, que podrían integrar parte de nuestra normalidad y de allí a la 'nueva normalidad' .

Que la sociedad epocal pospandémica nos imponga de algunas transformaciones profundas y otras no tan severas es cierto. Como también es muy probable, que muchas de ellas, terminen siendo asimiladas como valiosas aun cuando, el fantasma de la pandemia se haya retirado y entonces, no será ninguna 'nueva normalidad', sino la normalidad para un tiempo pospandémico.

Todo lo otro será provisorio, que no quiere decir de unos pocos días, será de varios meses quizás; pero escapa al pensamiento maduro decir, que habrá cuestiones que aun siendo contrarias a lo natural, serán la 'nueva normalidad'.6

Naturalizarlo de esa manera mediante el lenguaje corriente, es un primer síntoma alarmante por el cual se pueda creer que ciertas cosas -que desde ya no es el cubrebocas para las comidas, ese es solo el ejemplo- deben ser comprendidas impuestas por integrar la 'nueva normalidad' aparece como un exceso. Será en todo caso, las 'singularidad de lo excepcional'. De lo contrario parece, propiciarse una consideración descalificante y humillante a los ciudadanos sin más (Berger y Luckmann, 2008).

6 Desde otra perspectiva, pero que finalmente pueden ser utilizados varios de los argumentos. Canguilhem, Georges. Lo normal y lo patológico. México: F.C.E., 2009.. 


\section{REFERENCIAS BIBLIOGRÁFICAS}

- Amigo Fernández de Arroyabe, Luisa (ed) (2003). Humanismo para el siglo XXI. Bilbao: Universidad de Deusto.

- Andruet, Armando (2020). Estado de excepción sanitaria - Lateralidades morales, sociales y jurídicas. Buenos Aires: Astrea.

- Andruet, Armando (ed) (2020). Consecuencias jurídicas, institucionales, ambientales y sociales de la pandemia de COVID-19. E-book Academia Nacional de Derecho y Ciencias Sociales de Córdoba. Disponible en: https://www.acaderc.org.ar/2020/07/07/consecuencias-juridicas-institucionales-ambientales-y-sociales-de-la-pandemia-covid-19/

- Bauman, Zigmunt (2010). Mundo consumo - Ética del consumo en la aldea global. Buenos Aires: Paidós.

- Berger, Peter y Luckmann, Thomas (2008). La construcción social de la realidad. Buenos Aires: Amorrortu.

- Burnet, MacFarlane (2007). Historia de las enfermedades infecciosas. Madrid: Alianza.

- Cortina, Adela (2010). Justicia cordial. Madrid: Trotta.

- Delumeau, Jean (2019). El miedo en occidente. Madrid: Taurus.

- Du Gay, Paul (2012). En elogio de la burocracia -Weber, Organización, Ética. Madrid: Siglo XXI.

- Ducrot, Oswald y Schaeffer, Jean-Marie (1998). Nuevo diccionario enciclopédico de las ciencias del lenguaje. Madrid: Torrecifes, pág. 121 y ss.

- Foucault, Michel (1989). El ojo del poder. En Jeremy Bentham, El panóptico, Puebla: Premià.

- Gallino, Luciano (2005). Diccionario de Sociología. México: Siglo XXI, pág. 5 y ss.

- García Marzá, Domingo (2011). Ética empresarial - Del diálogo a la confianza. Madrid: Trotta.

- Garrigou-Lagrange, Reginald (1944). El sentido común. Buenos Aires: Desclée de Brouwer.

- Garzón Valdés, Ernesto (2004). Calamidades. Barcelona: Gedisa, pág. 199.

- Gracia, Diego y Peset, José (1978). La medicina en la baja edad media latina (siglos XIV y XV).

En Pedro Laín Entralgo, Historia Universal de la Medicina. Madrid: Salvat, T.IIII, pág. 347 y ss.

- Harari, Yuval (2014). Homo Deus - Breve historia del mañana. Madrid: Debate, pág. 295.

- Jonas, Hans (1995). El principio de responsabilidad - Ensayo de una ética para la civilización tecnológica. Barcelona: Herder.

- Konig, René (1968). Sociología de la moda. Buenos Aires: Carlos Lohlé.

- Lévinas, Emmanuel (2000). Etica e infinito. Madrid: La balsa de la Medusa, 2000.

- Lipovetsky, Gilles (1994). El crepúsculo del deber - La ética indolora de los nuevos tiempos democráticos. Barcelona: Anagrama, pág. 245 y ss.

- Mascaró y Porcar, José (1986). Diccionario Médico. Barcelona: Salvat, pág. 191.

- Mora, Antoni (2005). La inquietud y el cuidado - La tentativa biopolítica de Maurice Blanchot. En Javier Ugarte Pérez (compil.) La administración de la vida - Estudios biopolíticos.

Barcelona: Anthropos, pág. 153 y ss.

- Quéau, Philippe (1995). Lo virual - Virtudes y vértigos. Barcelona: Paidós, 1995.

- Sanmartín Bastida, Rebeca (2006). El arte de morir - La puesta en escena de la muerte en un tratado del siglo XV. Madrid: Iberoamericana.

- Sigerist, Henry (1946). Civilización y enfermedad. México: F.C.E.

- Snowden, Frank M. (2020). Epidemics and society. From the black death to the present, Connecticut, Yale University Press.

- Tucídides (1976). Historia de la guerra del Peloponeso. Madrid: Guadarrama, pág. 78.

- Van Dick, José (2016). Acerca de la cultura de la conectividad. Buenos Aires: Siglo XXI. 